\title{
SIMULATION AND OPTIMIZATION OF A NATURAL GAS PROCESSING FACILITY TO SALES GAS (LNG) USING ASPEN-HYSYS WITH EXERGY-PINCH CONCEPT
}

\author{
Philip Thomas Wakili \\ Department of Chemical Petroleum Technology (SLT) \\ The University of Jos, Jos, Plateau, Nigeria
}

Jock Asanja Alexander

Department of Chemical and Petroleum Engineering

The University of Uyo, Uyo, Nigeria

\begin{abstract}
Steady/Dynamic models for optimization of natural gas processing facility to sales gas with exergy pinch concept has been developed and reported in the literature. Such models are only validated at steady-state, which means the models can predict process performance at different operating points. However, without dynamic validation, there is no guarantee that the model in question would predict dynamic responses accurately. Plant data logs were provided by the University of Calgary, AspenTech, Canada. Two cases were considered: A natural gas processing facility which employs end-point exchanger model approach and weighted exchanger model approach to produce sales gas (LNG) is optimized to meet the LNG required dew point temperature $\left(-15^{\circ} \mathrm{C}\right)$ using a steady state flow. A conventional absorber temperature profile, reboiler duty were used for comparison. It is observed that the model satisfactorily predicts the pilot plant behavior under multiple process inputs and disturbances. All major units such as mixers, separators, heat exchangers, distillation column, adjust and balance in the base case has been simulated. The operating conditions are taken to match the field conditions of an ideal process plant. Peng Robinson (PR) equation of state (EOS) has been employed. The simulation was initially made offline with an ideal state inlet gas composition. The responses were recorded for various changes in the inlet gas composition and pressure. The performance of the plant was studied to ensure that the steady state operation of the plant is not significantly affected. This shall lead to maximum production using customer contractual limits.
\end{abstract}

Keywords - Aspen Modeling, Steady/Dynamics State, Exergy-Pinch Concept, Property Package (EOS)

\author{
Abubakar Abbas Jibril \\ Department of Petroleum \& Gas Engineering \\ The University of Salford, Manchester, Lancashire, UK \\ Israila Joshau John \\ Department of Chemical Petroleum Technology (SLT) \\ The University of Jos, Jos, Plateau, Nigeria
}

\section{INTRODUCTION}

Gas plants have several distinctive features that cause operation complexity. One unique characteristic is the fact that inlet feed stream conditions do not remain constant. This is due to the combination of feed streams from different well formations, variation of pressure, dew point temperature, flow and composition of inlet stream with passage of time and depletion of reservoirs. As a result, economic optimum set of plant operating process parameters such as temperature and pressure change. To obtain optimum production and meet required standards, mathematical modeling, exergy analysis \& optimization of gas processing plant is mandatory.

Computer Simulation is an important tool for analysis and design of chemical process. Oil and Gas processing is believed to be an area where Simulation could be used very advantageously because hydrocarbons and other organic compounds do not cause such troubles at calculations as strong polar and ionized compounds. This research is to counter $\&$ ensure that the above mentioned problems, that the steady state operation of the plant is not significantly affected (Ramzan et al., 2013).

In Oil \& Gas high boosting countries like the United States, Canada, Middle East etc, the natural gas product fed into the mainline gas transportation system must meet specific quality measures in order for the pipeline grid to operate properly. Consequently, natural gas produced at the wellhead, which in most cases contains contaminants and natural gas liquids, must be processed, i.e. cleaned, before it can safely delivered to the high-pressure, long-distance pipelines that is not within certain specific gravities, pressure, BTU content range, or water content levels will cause operational problems, pipeline 


\section{International Journal of Engineering Applied Sciences and Technology, 2020 \\ Vol. 5, Issue 6, ISSN No. 2455-2143, Pages 298-306 \\ Published Online October 2020 in IJEAST (http://www.ijeast.com)}

deterioration, or even cause pipeline rupture (Guild etal, 2009).

Natural gas is a vital commodity in the global energy market. Oil is the leading energy source. Next in importance, come coal and natural gas contributing almost $50 \%$ of the energy sources (Administration, 2012).

Natural gas is a clean source of energy and its popularity is expected to grow rapidly in the future because it presents many environmental advantages over oil and coal. Carbon dioxide $\left(\mathrm{CO}_{2}\right)$, a greenhouse gas related to global warming, is produced from oil and coal at rate approximately 1.4 to 1.75 times higher than that produced from natural gas. Also, nitrogen oxides (NOx), greenhouse gas and a source of acid rain, are formed from burning fuel. NOx produced from burning natural gas are approximately $20 \%$ less than those produced from burning oil and coal (SAPUAN etal, 2008), (Kidnay and Parrish, 2006).

\subsection{Process Description}

The facility was modeled using ASPEN-HYSYS using PengRobinson equation of state. The gas from upstream process with a hydrocarbon content ranging from $\mathrm{C} 1$ to $\mathrm{C} 5$ is passed through a separator where dense carbon components are collected at the lower end of the separator. The less dense components are passed through tube section of a shell and tube heat exchanger. During this process, the less dense hydrocarbon gas is chilled by running low temperature separator (LTS) gas in a co-current direction to each other. The third stage of the process would be to further reduce the temperature of the less dense hydrocarbon by running the stream through a chiller. The chiller cools the gas by employing a refrigerant like propane. The chiller will reduce the temperature of the hydrocarbon gas stream further knocking off liquids in the stream since vapor stream with higher dew point condenses to liquids and are collected in the LTS. By virtue of density, the LTS liquids are collected in the lower end of the separator while the LTS vapor is used in the heat exchanger to reduce the temperature of gas from the first separator. A balance and adjuster are added to ensure that the sales gas dew point specifications are met in all modes of operation by comparing the HC Dew point stream temperature to the target temperature and adjusting the Gas to LTS temperature to reach that value.

A natural gas processing facility (plant) which can employ both end-point exchanger model approach and weighted exchanger model approach to produce sales gas (LNG) is simulated and optimized. This has the possibility of reducing overall LNG energy cost at the same time increasing the benefits to at least $20 \%$. It is for this reason of interest to discover which among the exchanger model approaches (end point and weighted) can be applied to obtain the optimum required maximum optimized efficiency benefits, Sales Gas
(LNG) temperature dew point and adequate process conditions towards meeting future demands. Next, what the limitations are of this implementation and how the end point approach compares to the weighted approach. The problem statement is for this reason separated into four parts:

- How can it ensure that the steady state operation of the plant is not significantly affected (bumpless shift) which will lead to maximum production using customer contractual limits?

- How can the two exchanger model approach be applied to obtain the optimal exergy optimize, efficiency, sales Gas (LNG) dew point temperature and adequate process conditions towards meeting future demands and perfect cost benefits?

- What are the limitations of the used implementation when exergy analysis and optimization is been carried out on the process?

- How does the end point approach simulation method compare to the weighted method with respect to increasing efficiencies and deviations which might occur in the whole process equipment's from the reversible to irreversible process?

This would basically the model the process plant that uses propane refrigeration to condense liquids from the feed and a distillation tower to process the liquids. Sales gas (LNG) is obtained at the required dew point temperature. The flow sheet for this process appears below:

The combined feed stream enters an inlet separator, which removes the free liquids. Overhead gas from the Separator is fed to the gas/gas exchanger, where it is pre-cooled by already refrigerated gas. The cooled gas is then fed to the chiller, where further cooling is accomplished through exchange with evaporating propane (represented by the C3Duty stream). In the chiller, which will be modeled simply as a Cooler, enough heavier hydrocarbons condense such that the eventual sales gas meets a pipeline dew point specification. The cold stream is then separated in a low-temperature separator (LTS). The dry, cold gas is fed to the gas/gas exchanger and then to sales (LNG), while the condensed liquids are mixed with free liquids from the inlet separator. These liquids are processed in a depropanizer column to produce a low-propane-content bottoms product. 


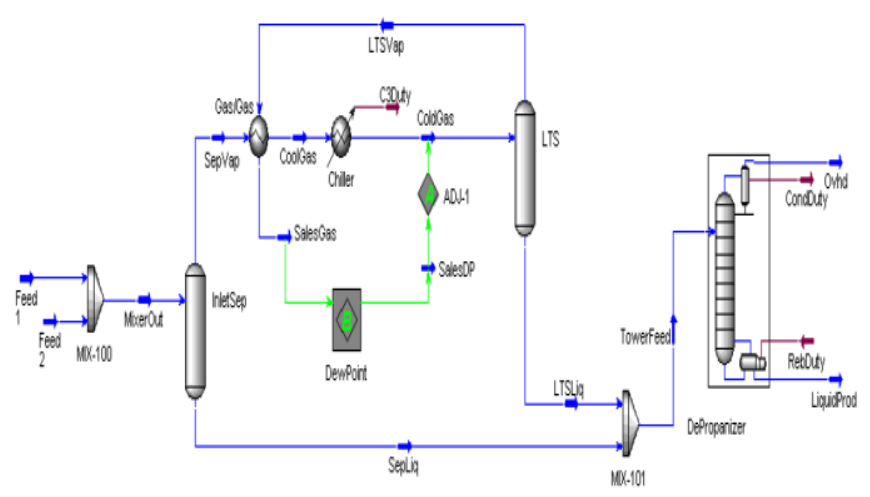

A simplified representation of natural gas processing facility Flow Diagram (Intergovernmental Panel for Energy Information and Administration, 2007)

\subsection{Motivation}

To understand the operational characteristics of a natural gas processing plant to sales gas (LNG) and identify possible difficulties that may arise, further process analysis is required via modelling and simulation. The overall commonly modelled process are employs in both academically and commercially in process simulators like Aspen HYSYS ${ }$, Aspen Plus® and gPROMS®. Although there are a number of pilot and demonstration plants currently running campaigns (Wang et al., 2011), acquiring data of these campaigns is difficult, making model validation a challenging task. Nevertheless, some data are available in the literature (Cottrell et al., 2009). End point exchanger model approach (EP) deals with non- linear curves problem as well as state-constrains thereby allowing further objective optimization to be carried out. The main issue of weighted exchanger model approach (WA) is that is available only for counter-current exchangers and cannot deal with state-constrains directly, resulting in results which are in practice infeasible. Furthermore, the optimized steady state simulated plant input may suffer from bumpless shift ${ }^{1}$. However, the FT correction factor is not considered when using the weighted model approach. Besides these two issues, the weighted model is technically expensive as it takes much longer time (45 minutes-1hour) to converge. Moreover, implementation of the weighted model approach may constitute higher hydrates because of the phase change of components in one or both sides.

\footnotetext{
${ }^{1}$ Bumpless shift refers to optimized non-unique process variables to the input, which causes the input profile-profile to behave irregularly.

To overcome the issues of the weighted model approach towards meeting required LNG process variable conditions, a literature study has been conducted which concluded that the end-point model approach should provide a solution. The end-
}

point model is used in the chemical industry to solve the issue of handling state-constraints. Besides, the approach can have implemented using rating calculations if detailed geometry information is provided. Although the end-point model approach may provide a solution to the issues of weighted model approach, it is known to have several limitations as well. The first limitation is the heating curve is not broken into intervals thereby allowing energy balance across the interval. The second limitation is that it does not constitute a phase change of components. It is investigated how the end-point model approach can be applied to a simulated natural gas processing facility to meet required sales gas (LNG), what the limitations are of the current implementation and if the performance is comparable to the results obtained by the weighted model approach (WA).

As a systematic tool for optimal design and performance, exergy-pinch concept has been applied to evaluate exergy destruction, exergy loss and exergy efficiency in the overall process which helps in identifying unit operations within the system required to be optimized and manipulated for optimal output. Consequently, irreversibility occurs less at the endpoint model approach (EPA) because of constant temperature and pressure difference which indicates a steady overall plant operation. Also, at the first stage of the simulation were the mixer unit operation was used, water in the natural gas stream was $0.05 \%$ by mole. At the end of the process simulation, the composition of water was reduced to $0.001 \%$ by mole. Furthermore, there was a sharp increase in the percentage composition of methane $(0.7 \%)$ by mole. An increase in the circulation rate and temperature of the exchanger and distillation column contribute to efficient water pickup. The required dew point temperature $\left(-15^{\circ} \mathrm{c}\right)$ and other vital process variables for efficient plant operation was not clearly obtained. A cost benefit analysis between the ASPEN-HYSYS simulated natural gas facility to sales gas (LNG) based technique and that of the conventional molecular sieves based process gave the equipment to be $\$ 237,075$ and $\$ 800,000$ respectively. The process is analyzed with the validated model for dew point temperature Section 5. Conclusions are drawn in Section 6, along with recommendations for future work.

\section{MODEL DeVElopmenT}

\section{A. Motivation for using the Peng-Robinson fluid package and equation of state (EOS)}

Solving equations of state allows the design to find the specific volume of a gaseous mixture of chemicals at a specified temperature and pressure. Without using equations of state, it would be virtually impossible to design a chemical plant. By knowing this specific volume, determine the size and thus the cost of the plant. (Hamid etaal, 2013)

HYSYS currently offers the enhanced Peng-Robinson (PR) and Soave-Redlich-Kwong (SRK) equations of state. Of these, 


\section{International Journal of Engineering Applied Sciences and Technology, 2020 \\ Vol. 5, Issue 6, ISSN No. 2455-2143, Pages 298-306 \\ Published Online October 2020 in IJEAST (http://www.ijeast.com)}

the peng-Robinson equation of state generates all required equilibrium and thermodynamic properties directly.

The PR and SRK packages contain enhanced binary interaction parameters for all library hydrocarbon-hydrocarbon pairs (a combination of fitted and generated interaction parameters), as well as for most hydrocarbon-nonhydrocarbon binaries.

\section{1) EOS Mathematical Formulae}

The ideal gas equation of state, which relates the pressure, temperature, and specific volume, is a familiar equation:

$p \mathrm{~V}=\mathrm{nRT}$ or $p=\mathrm{RT}$ where $v=$

The term $p$ is the absolute pressure, $V$ is the volume, $\mathrm{n}$ is the number if moles, $R$ is the gas constant, and $T$ is the absolute temperature. The units of $R$ have to be appropriate for the units chosen for the other variables. This equation is quite adequate when the pressure is low (such as one atmosphere).

However, many chemical processes take place at very high pressure. Under these conditions, the ideal gas equation of state may not valid representation of reality.

Other equation of states has been developed to address chemical pressure. The first generalization of the ideal gas law was van der Waals equation of state.

$\mathrm{P}=\quad-(2)$

This extension is just a first step, however, because it will not be a good approximation at extremely high pressures. The Redlich-Kwong equation of state is a modification of van der Waal"s equation of state, and then was modified further by Soave to give the Soave-Redlich-Kwong (SRK) equation of state is Peng-Robinson equation of state. (Hypotech, 2012)

The table (1) provides a comparison of the formulation used in HYSYS for the SRK and PR equations of state. (Waall's, 1996)

\section{Table 1}

\begin{tabular}{|c|}
\hline SRK-EOS[7] \\
\hline$P=\frac{R T}{(\nu-b)}-\frac{a}{\nu(\nu+b)}$ \\
\hline$a=0.42747 \frac{R^{2} T_{c}^{2}}{P_{c}} \alpha\left(T_{r}, a\right)$ \\
\hline$b=0.08664 \frac{R T_{c}}{P_{c}}$ \\
\hline$(\alpha)^{0.5}=1+\left(1-\mathrm{T}_{\mathrm{r}}^{0.5}\right)\left(0.48508+1.55171 \omega-0.15613 \omega^{2}\right)$ \\
\hline
\end{tabular}

Peng-Robinson Equation of State (International CAD Hypotech, 2012)

$$
P=\frac{R T}{V-b}-\frac{a \alpha(T)}{V(V+b)+b(V-b)}
$$

where

$a=0.45724 \frac{R^{2} T_{c}^{2}}{P_{c}}$

$b=0.07780 \frac{R T_{c}}{P_{c}}$

$\alpha(T)=\left[1+m\left(1-T_{r}^{1 / 2}\right)\right]^{2}$

$m=0.37464+154226 \omega-0.26992 \omega^{2}$

B. Buiding the main "simulation" model (step-by-step)

- Defining components list and fluid package

- Adding streams and unit operations

- Adding logical operation (Balance and Adjust)

\section{Defining the simulation basis}

For this case, the Peng Robinson EOS will be used with

Following components: N2, H2S, CO2, C1, C2, C3, i-C4, n$\mathrm{C} 4$, i-C5, n-C5, C6, C7+ and $\mathrm{H} 2 \mathrm{O}$.

1. Create a new case.

Import the fluid package, Gas Plant, which you saved in Module 1

\section{(Getting started).}

\section{Adding a feed stream}

Add a new material stream with the following value:

Name to Refrig, Temperature $15^{\circ} \mathrm{C}\left(60^{\circ} \mathrm{F}\right)$ 
Published Online October 2020 in IJEAST (http://www.ijeast.com)

Pressure 6200 kPa (900 psia)

Flow Rate 1440 kgmole/h (3175 lbmole/hr)

Table 2; Material Stream (Inlet Gas Composition)

\begin{tabular}{|l|l|}
\hline $\begin{array}{l}\text { Feed Gas Flow rat to Unit } \\
\text { (6.000 MMSCFD), Feed } \\
\text { Gas Composition in (Mole } \\
\text { Percent) }\end{array}$ & \\
\hline $\mathrm{N}_{2}$ & 0.0066 \\
\hline $\mathrm{H}_{2} \mathrm{~S}$ & 0.0003 \\
\hline $\mathrm{CO}_{2}$ & 0.0003 \\
\hline $\mathrm{C}_{1}$ & 0.7575 \\
\hline $\mathrm{C}_{2}$ & 0.1709 \\
\hline $\mathrm{C}_{3}$ & 0.0413 \\
\hline i- $\mathrm{C}_{4}$ & 0.0068 \\
\hline n- $\mathrm{C}_{4}$ & 0.0101 \\
\hline $\mathrm{i}-\mathrm{C}_{5}$ & 0.0028 \\
\hline n- $\mathrm{C}_{5}$ & 0.0027 \\
\hline $\mathrm{C}_{6}$ & 0.0006 \\
\hline $\mathrm{H}_{2} 0$ & 0 \\
\hline $\mathrm{C}_{+}+$ & 0.0000 \\
\hline $\mathrm{S}_{4}$ & \\
\hline
\end{tabular}

Source: www.hypotech.com (AspenTech, Canada, 2014)

\section{1) Exergy balance and irreversibilities}

Exergy balance can be expressed as

$\grave{\mathrm{E}}_{\text {in }}+\grave{\mathrm{E}}_{\mathrm{Q}}$ in $=\grave{\mathrm{E}}_{\text {out }}+\grave{\mathrm{E}}_{\mathrm{Q}}$ out $+\grave{\mathrm{W}}_{\mathrm{sh}}+\grave{\mathrm{I}}$ (21)

Where the subscripts in and out indicate inlets and outlets, respectively.

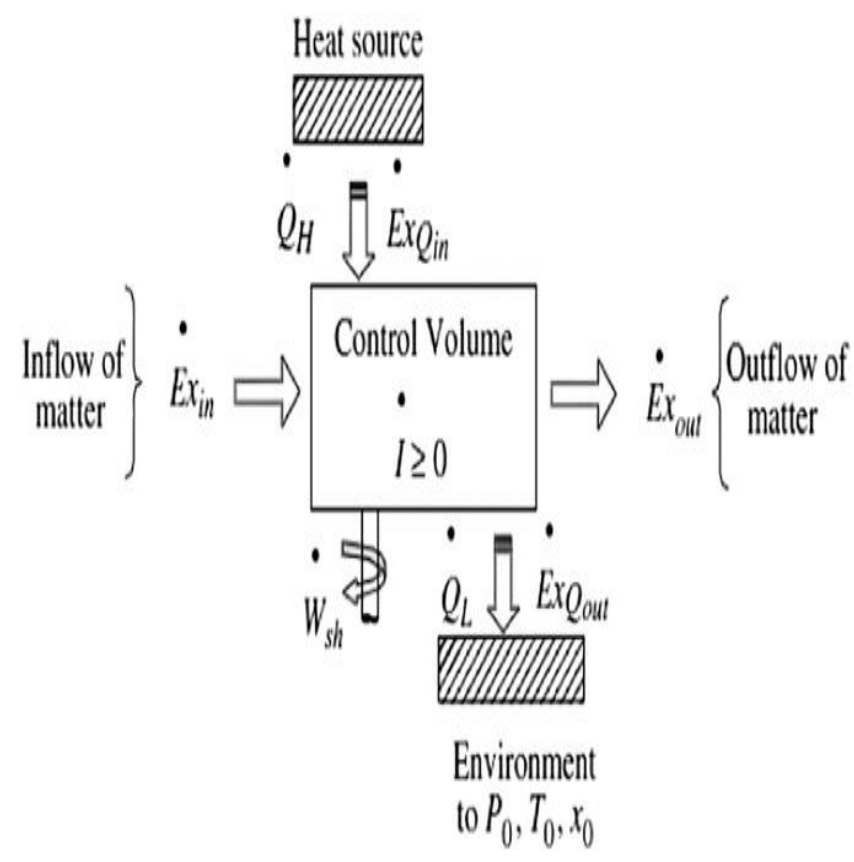

Figure 1: Flow of matter and energy in a control region of a steady state process, adapted From Kotas (1995)

\section{2) Dewpoint Temperature (Graphical Details)}

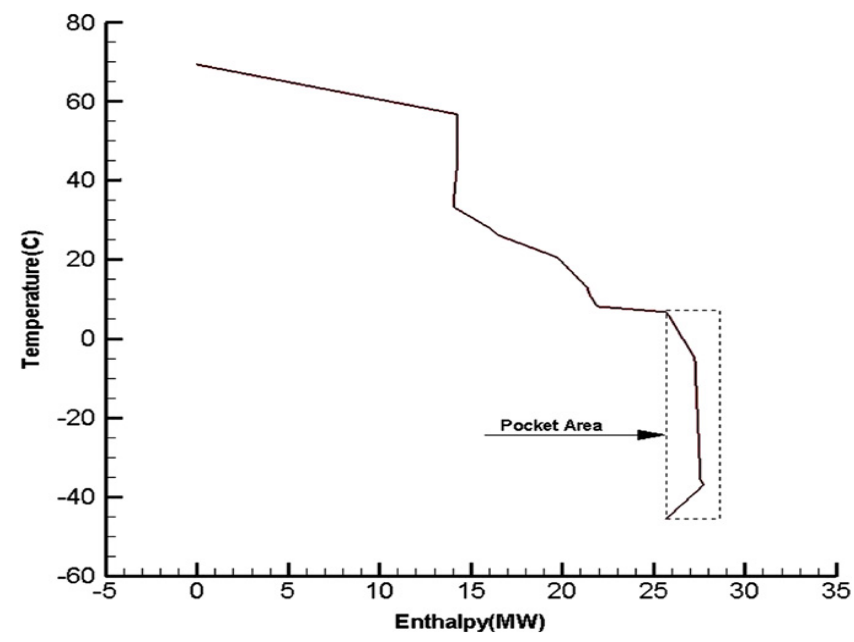

Figure 2: Temperature Vs Enthalpy (1)

- Both the graphs above and below shows similar steady optimal solution. Temperature with Enthalpy synergy is positive. Activation of result constrains is highly minimal. 


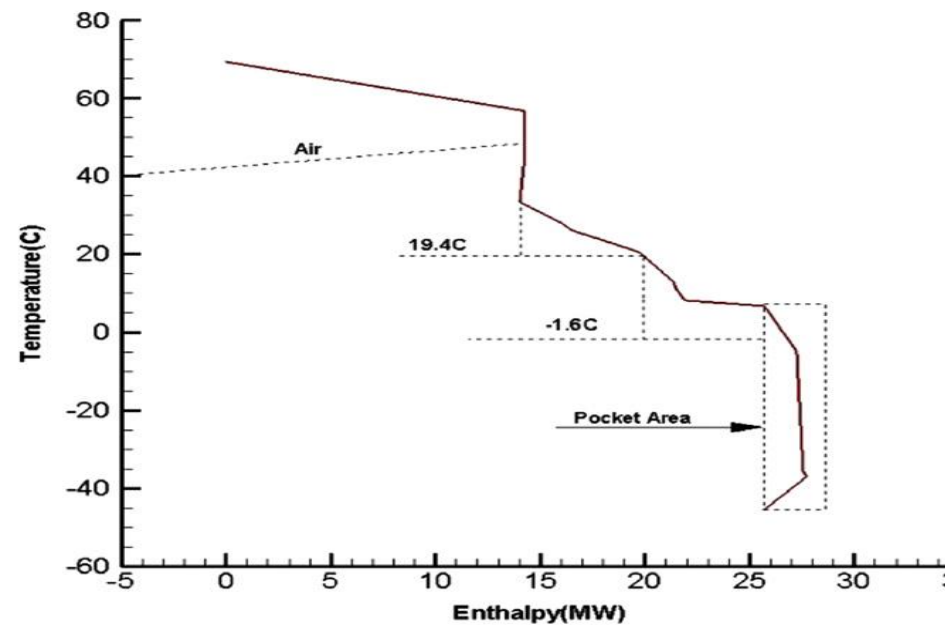

Figure 3: Temperature Vs Enthalpy Graph (2)

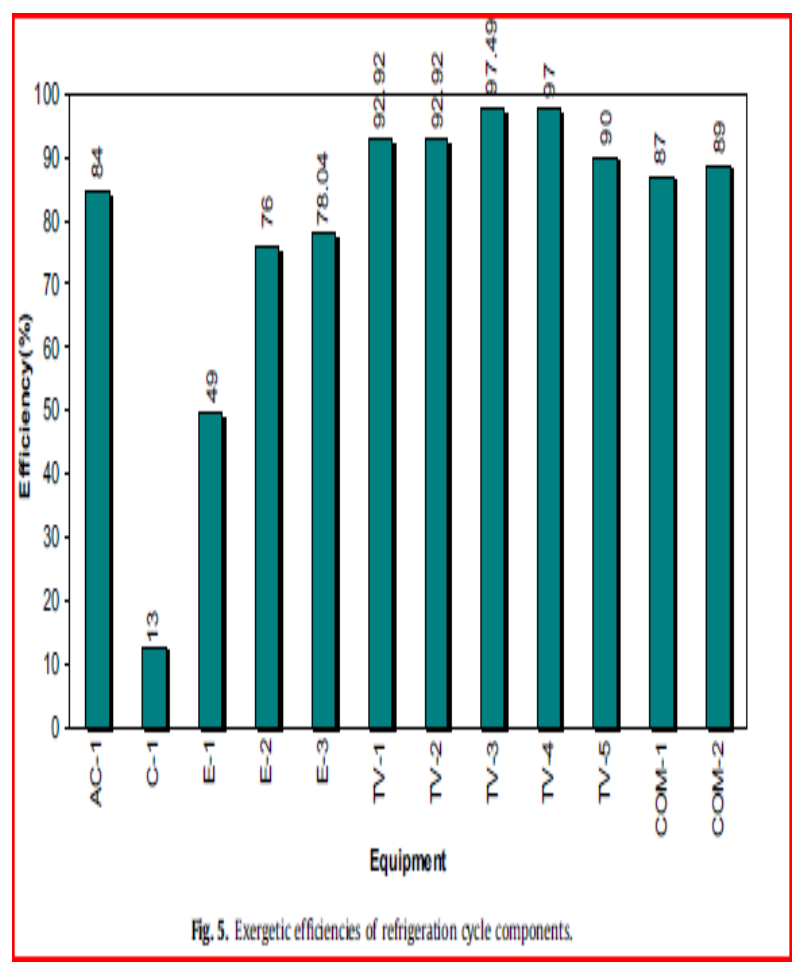

Figure 4: Efficiency Vs Equipment Chat (B. Ghorbani et al, 2014)

From above (Figure 3), all components of the refrigeration system demonstrated some sort of irreversibility. The exergy analysis showed that the lowest efficiencies belonged to heat exchanger C-1(13\%), E-1 (49\%) and E-2 (76\%); therefore, a large amount of irreversibilities belonged to evaporator (E-2), air condenser (AC-1) and TV-1 throttle valve of the refrigeration cycle. The results showed that TV-1 had nearly high irreversibilities because of the high pressure difference which indicated that other throttle valves had the highest amount of efficiency and lowest exergy destruction; so the performance of these devices was the nearest to the ideal manner.

Consequently, from below (Figure 5) shows similar ideal manner in terms of performance. Reflux ratio is $0.9 \%$ and other internal variables such as NetLiquid, NetVapour, NetFeed, NetDraw idealizes a high efficiency at the least energy use.

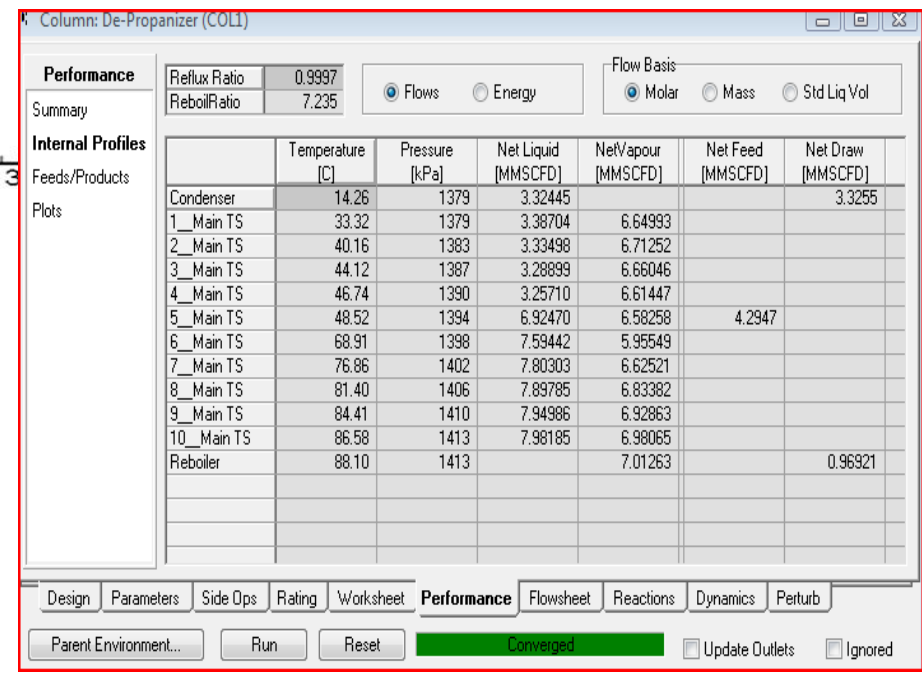

Figure 5: Column Internal Profiles showing performance "Efficiencies"

- Tray positions from the condenser down to the reboiler are constant, thereby eliminating every bottle necks towards ascertaining a perfect simulation.

- SalesGas (LNG) required process conditions (dew point temperature) are $\mathbf{1 5}^{\circ} \mathrm{C}$ which is perfect for an ideal situation.

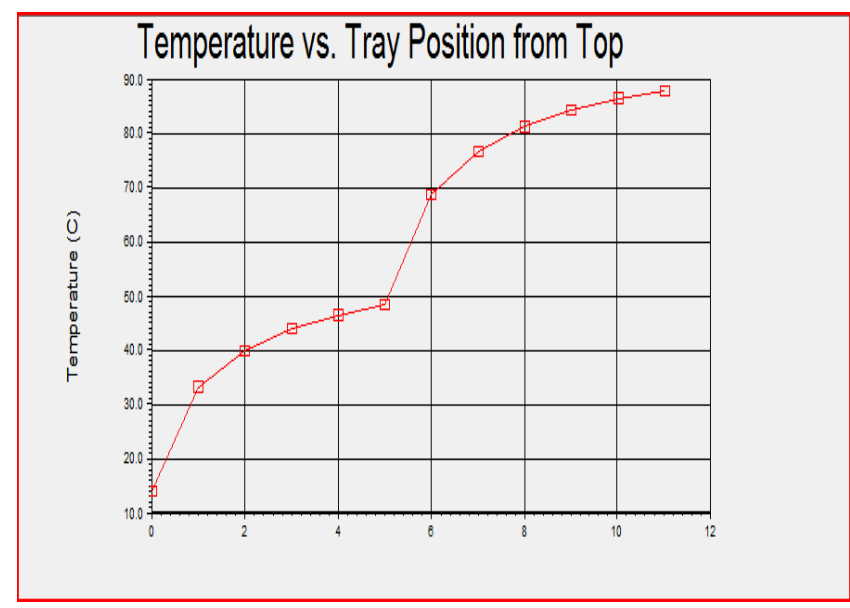

Figure 6: Temperature Vs Tray Positions (1) 
- In Comparison of both the two graphs Activation of the constraints results in different profiles of the variables. The dynamics of both models are comparable, steady and active. SalesGas(LNG) required Dew point temperature $\left(-15^{\circ} \mathrm{C}\right)$ has been achieved.

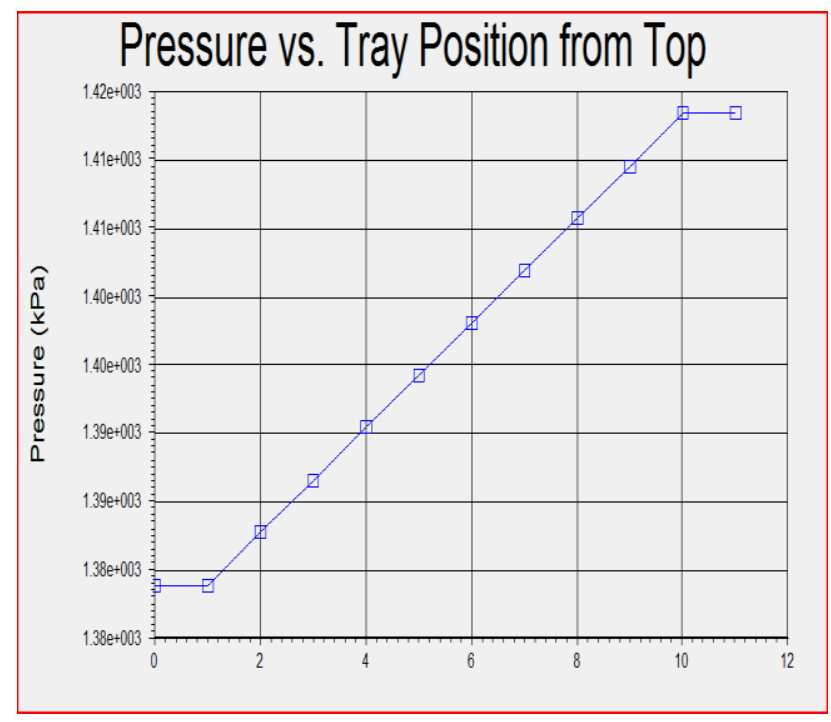

Figure 7: Temperature Vs Tray Position (2)

\section{DISCUSSION}

"COST BENEFIT" COMPARATIVE ANALYSIS OF ASPEN-HYSYS SIMULATED BASED RESULT WITH A CONVENTIONAL PLANT USING MOLECULAR SIEVES (LNG)

A comparative analysis was carried out using data from a typical gas plant. Molecular sieve was used by the plant refrigeration unit. ASPEN- HYSYS was used to simulate the process using the same composition.

Table 3: Cost Benefit Analysis

\begin{tabular}{|l|l|l|}
\hline Component Parameter & $\begin{array}{l}\text { ASPEN- } \\
\text { HYSYS } \\
\text { Simulated gas } \\
\text { natural } \\
\text { facility to sales } \\
\text { gas (LNG) }\end{array}$ & $\begin{array}{l}\text { Conventional } \\
\text { LNG Plant NLNG } \\
\text { using molecular } \\
\text { sieves) }\end{array}$ \\
\hline Empty Vessels & $\$ 100,000$ & $\$ 180,000$ \\
\hline Installation (Labour) & $\$ 20,000$ & $\$ 50,000$ \\
\hline $\begin{array}{l}\text { Total cost of all unit } \\
\text { operations (Mixers, }\end{array}$ & $\$ 117,075$ & $\$ 593,580$ \\
\hline
\end{tabular}

\begin{tabular}{|c|c|c|}
\hline $\begin{array}{l}\text { Separators, Pinch } \\
\text { valve, Distillation, } \\
\text { Heat exchangers) }\end{array}$ & & \\
\hline Regeneration & $\begin{array}{l}\text { Lesser } \\
\text { mins })\end{array}$ & $\begin{array}{l}\text { Time consuming } \\
\text { (6-7 hours) }\end{array}$ \\
\hline $\begin{array}{l}\text { Total } \\
\text { Equipment/Plant } \\
\text { cost }\end{array}$ & $\$ 237,075$ & $\$ 800,000-980,000$ \\
\hline
\end{tabular}

Note: All equipment costs estimates were taken from the online chemical plant equipment cost Estimator at www.mhhe.com/engcs/chemical/peters/date/ce.html

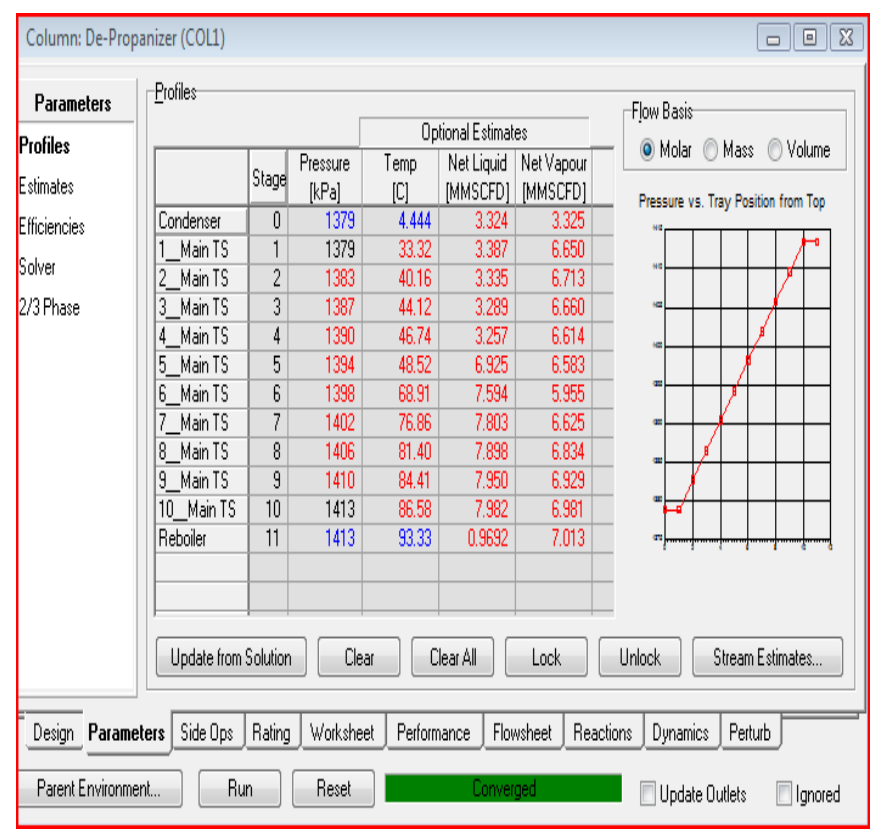

Figure 8: Distillation Column (Profiles)

Some vital points can be deduced from above profile:

- Constant presure increase with respect to the number of trays ensures a low hydrate formation

- Their exist a steady temperature difference from the condenser to the reboiler which gives rise to the plant to converged (Green)

- At the optional estimates, Net Liquid and Net Vapour are slightly larger but pressure build up is steady which shows a potential increase in the efficiency.

- Overal process plant is stable. 


\section{International Journal of Engineering Applied Sciences and Technology, 2020 \\ Vol. 5, Issue 6, ISSN No. 2455-2143, Pages 298-306 \\ Published Online October 2020 in IJEAST (http://www.ijeast.com)}

\section{CONCLUSION}

This paper presents an investigated to what extent the ASPENHYSYS process simulation software is able to solve and optimize a natural gas processing facility to Sales Gas (LNG) with exergy pinch concept. The problem is divided into three parts. Firstly, it has been demonstrated how the two exchanger model approach can be simulated and applied to meet the required Sales Gas (LNG) dew point temperature, optimal exergy, optimized efficiency and overall adequate process conditions. Secondly, the current implementations have been verified and it has been researched what its limitations are, and also how exergy analysis can be applied to evaluate the magnitude of exergy destruction, exergy loss and energetic efficiency in the overall process which helps in identifying unit operations within the system needed to be optimized and manipulated. Thirdly, the end point approach (EP) has been compared to the weighted approach. Also, the current implementation of ASPEN-HYSYS natural gas simulation with end point exchanger model approach is still limited to about $(0.6 \%)$ of higher hydrocarbon components and sensitive to hydrate formation. This may improve by subsequent research, which should include the following recommendations.

The application of ASPEN-HYSYS in natural gas processing can be improved on two points. The first is the use of a higher version of the latest software ASPEN-HYSYS (V8.6). This latest HYSYS software applies the availability of new features such as: integrated exchanger sizing and rating, integrated economic analysis, improved thermal conductivity predictions for heavy hypo fractions and integrated energy analysis. This drastically reduce the overall variable manipulations to be carried out (if their exist any un-converged unit operation) and general improve the precision of the solution and the required optimization time. The second point of improvement is the fact that any limitations for the process plant not to converge to optimal optimization are not only based on the complexity of the task to be simulated but also the HYSYS optimizer. Therefore, "Integrated HYSYS optimizer" been added in the Hysys latest features will give a more realistic outcome and may improve the optimization performance as well.

The implementation of achieving a much better Sales Gas (LNG) (dew point temperature $\left(-15^{\circ} \mathrm{C}\right)$ ) can be improved by using an integrated end point exchanger model approach or even an integrated newly designed refrigeration processing system. Firstly, the integrated end point model approach also deals with improved non-linear heat curves problem. The integrated EP model is also able to deal with state-constraints and allows further multi-objective optimization. Secondly, the Integrated EP models (sizing and rating) are based on constant flow-rates, but the optimal flow rates are varying. It may for this reason be better to obtain process conditions which are based on more realistic varying flow rates with less manual manipulation thereby eliminating the rate of hydrate formation to completely minimal.

\section{REFERENCE}

[1] APHORNRATANA, S. \& EAMES, I. W. . "Thermodynamic analysis of absorption refrigeration cycles using the second law of thermodynamic method". International Journal of Refrigeration, 18 (4), 244-252, 1995..

[2] CERCI, Y., CENGEL, Y. A. \& WOOD, B.. "The minimum work requirement for distillation process. Twelfth International Symposium on Transport Phenomena", (ISTP-12).344-667, 2000

[3] CHEBBI, R., AL MAZROUI, K. A. \& ABDEL JABBAR, N. M. . 'Study compares C2-recovery for conventional turboexpander". GSP. Oil \& Gas Journal, 106 (46).854-947, 2008.

[4] FABREGA, F. M., ROSSI, J. S. \& D ANGELO, J. V. H.. "Exergetic analysis of the refrigeration". International Journal of Applied Sciences, 65 (6), 2006.

[5] GAGGIOLI, R. A. etal. "International Journal of Applied Thermodynamics. Available energy and exergy", 1, 1e8., 234-567,1998..

[6] KANOGLU, M.. "Exergy analysis of multistage cascade refrigeration cycle used for natural gas liquefaction". International Journal of Energy Research, 26, 763-774, 2002.

[7] KIDNAY, A. J. \& PARRISH, W. R. . "Fundamentals of Natural Gas Processing, Taylor \& Francis", 234-657, 2006.

[8] KOTAS, T. J. . "The Exergy Method of Thermal Plant Analysis, Butterworths", London.456-234,1995

[9] MAFI, M., NAEYNIAN, S. M. \& AMIDPOUR, M. . "Exergy analysis of multistage cascade", 345-245, 2008.

[10] MANNING, F. S. \& THOMPSON, R. E.. "Oilfield Processing of Petroleum, PennWell Publishing Company", 1991.

[11] MEHRPOOYA, M., JARRAHIAN, A. \& JARRAHIAN, M. R. Simulation and exergy-method 234-543, 2006

[12] RUSSEL, T. H. . "Straight refrigeration still offers processing flexibility. Oil \& Gas Journal", 4, 66-72, 1977.

[13] ADMINISTRATION, U. S. E. I.. "Annual Energy Review . Energy Information Administration", 234-456, 2012.

[14] ASPENTECH . "Simulation \& Optimization- SteadyState. Aspen Engineering Suite ${ }^{\mathrm{TM}}$ (AES), 1, 2014.

[15] BURBY, M. etal. Heat Echanger Designs. University of Salford, Manchester, 114-456, 2014.

[16] CHANGE, E. A. \& LEE, E. A.. "Study on determination of optimal operating conditions of single mixed 
International Journal of Engineering Applied Sciences and Technology, 2020

Vol. 5, Issue 6, ISSN No. 2455-2143, Pages 298-306

Published Online October 2020 in IJEAST (http://www.ijeast.com)

refrigerant process for LNG FPSO. Hyundai Heavy Industries", 9, 2011.

[17] COULSON \& RICHARDSON . "Chemical engineering plant design and simulation". 25th ed., 2002

[18] LUYBEN \& TYREUS 1990. "Process Modeling Simulation and Control for Chemical Engineers";. 2nd ed., 1990.

[19] PARTHO, S. R. \& RUHUL, A. M. 2011. "Aspen-HYSYS Simulation of Natural Gas Processing Plant. Journal of Chemical Engineering", IEB, Vol. ChE. 26, 2011.

[20] SAPUAN, R. B.. "DATA VALIDATION OF SMALLSCALE LNG SYSTEM. SIMULATION \& DATA VALIDATION OF SMALL-SCALE LNG SYSTEM", 1.195294, 2008. 